\title{
A mentalising education programme for community pharmacy workforce
}

\author{
Christina Fosgerau ${ }^{1}$ (D), Nanna Broch Clemmensen ${ }^{1}$ iD Gitte Reventlov Husted $^{2}$ iD , Susanne Kaae $^{1}$ (D), \\ Charlotte Rossing ${ }^{2}$ \\ ${ }^{1}$ University of Copenhagen, Denmark \\ ${ }^{2}$ Research and Development, Pharmakon - Danish College of Pharmacy Practice, Denmark
}

\author{
Keywords \\ Community pharmacy \\ Emotion \\ Healthcare counselling \\ Mentalise \\ Psychoeducation
}

\author{
Correspondence \\ Christina Fosgerau \\ Department of Nordic Studies and \\ Linguistics \\ University of Copenhagen \\ Denmark \\ fogtmann@hum.ku.dk
}

\begin{abstract}
This article describes the development and content of the continuing education programme "Counseling first hand - understanding the customer and yourself through mentalising". The education programme is targeted at the community pharmacy workforce and aims at increasing the pharmacy workforce' awareness of mental states in pharmacy counselling in order to ultimately centre the interaction around the customer's perspectives. As such, the education programme combines the traditions of pharmacy practice with a psychologically-based theory of interaction, i.e. mentalising. The education programme is developed between partners from the University of Copenhagen and from Pharmakon-the Danish College of Pharmacy Practice and is funded by the European Institute of Innovation and Technology (EIT) Health. The continuing education programme spans four months and combines physical attendance with online modules.
\end{abstract}

\section{Introduction}

Acting as a primary frontier in the Danish healthcare system, the community pharmacy has the potential to help patients improve appropriate medication use and thus the therapeutic outcome. While significant problems are solved every day at the pharmacies (ElSouri et al., 2020), patients need to share their perspectives in order for the pharmacy workforce to provide better support for patients' medication use (Murad et al., 2017; Langberg et al., 2019). Studies on pharmacy interactions show that patients' perspective of sharing is rarely sought out actively by pharmacy staff during the desk meeting (Kaae et al., 2014; Olsson et al., 2014; Fosgerau \& Kaae, 2021; Qudah et al., 2021).

This lack of engagement by the patient might be related to the pharmacist's counselling practice. It has been demonstrated that pharmacy staff primarily focus on providing medical information to patients, while only infrequently asking questions exploring patients' experiences, perceptions and preferences concerning their prescribed medication (Chong et al., 2014; Koster et al., 2015; Wolters et al., 2017). Thus, the interaction at the pharmacy counter largely consists of information transmission and is hereby underpinned by the professionals' agenda. The transmission of information is, and has been, a central part of the community pharmacy societal and institutional roles of the workforce and is in many countries part of the community pharmacies legislative obligations (Svensberg et al., 2015; Benrimoj \& Fernandez-Llimos, 2020). However, for communication to be valuable, the information must be relevant for the patient.

Patients have privileged access to their own inner narrative and mental states, which constitute the basis for what might be deemed relevant for them. In this view, the task of the pharmacy professionals becomes one of exploring the patients' perspectives in order to gauge the relevancy of what to communicate. It might 
seem that identifying what a patient perceives as relevant is an exercise in abstract mindreading. However, it is the foundation of this article and the education programme that is described here that by creating awareness of and training professionals' mentalising-abilities, professionals might have a skillbased reference point for gauging relevancy for patients.

Mentalising refers to the capacity of engaging curiously with one's own and others' mental states and seeking to explore and understand these. This capacity can be trained (Haslam-Hopwood et al., 2006) and training targeted at physicians, nurses and psychologists have already been suggested (Welstead et al., 2018; Satran et al., 2020). In both a long term intervention (Satran et al., 2020) and in a short term intervention (Welstead et al., 2018), researchers found that training professionals' mentalising awareness increased professionals' knowledge and application of mentalising in healthcare interactions. As such, alongside enabling pharmacy staff to better attend to the patient's perspectives, training their mentalising capacity will also raise their awareness towards and understanding of their own mental states as they interact with patients.

Based on video recordings of 100 pharmacy encounters at Danish pharmacies, Fosgerau \& Kaae demonstrated that unrecognised mental states within pharmacy staff themselves prevent them from engaging with patients' cues towards medication experiences. Thus, enhancing pharmacy staff's mentalising capacity is beneficial in two aspects: it will enable them to explore and understand medication-related aspects that are relevant to the specific, unique patients they are engaging with and thus establish patient-centred communication. Furthermore, it will enable the workforce to more aptly consider their own mental states.

Besides furthering pharmacy staff's ability to engage with patients' perspectives, including recognising own perspectives, the capacity of mentalising is in itself a health-promoting capacity. The ability to understand the meaning of other people's behaviour and the way this behaviour affects oneself promotes an experience of well-being and protects professionals from the impact of distressing events and adversity (Schwarzer et al., 2021). The buffering effect of mentalising appears relevant in a pharmacy practice context; recent studies show that more than $60 \%$ of pharmacists report experiencing high levels of burnout. In fact, pharmacists (including the community pharmacy workforce) report one of the highest burnout rates among healthcare professionals (Padgett \& Grantner, 2020). There are several underlying causes for stress and burnout in the pharmacy workforce, amongst them being time constraints and performance metrics (Bridgeman et al., 2018). Preventing and overcoming stress and burnout in healthcare professionals includes leadership involvement, peer support and awareness of chosen incentives. Such initiatives can be supplemented by a psychologically informed education programme professionalising staff's communicative and self-care abilities in the complex and demanding context of community pharmacy work-life.

Pharmaceutical care as a concept has included the patient perspective since its origin with a focus on achieving positive patient outcomes at the community pharmacy, which has been tested in many intervention programmes (Liekens et al., 2014; Liekens \& Foulon, 2019; Steed et al., 2019; Ceulemans et al., 2021). These intervention research and mappings of practices have predominantly employed a quantitative scope and focused on offering significant pharmacotherapeutic information, e.g. identifying and solving drug-related problems of the pharmacy workforce (Patwardhan et al., 2014; Kari et al., 2018; Liekens \& Foulon, 2019; Presley et al., 2019). This previous research has largely focused on the professional perspective rather than the patient perspective.

With the present education, the point of departure is anchored within humanities and the framework of mentalising. Thus, the programme is theory-driven and concerned with the unique perspectives of the individuals and how these perspectives are addressed and handled in pharmacy encounters. The combination of this framework with communication skills and pharmacy practice perspectives is a novel approach in pharmacy education. The present article describes a new professional continuing education programme for the community pharmacy workforce, aimed at increasing their mentalising capacity towards the patients they meet and their own faculties, in order to ultimately promote patients perspective sharing in the pharmacy encounter and thus enable the pharmacy workforce to help patients improve their medication use.

\section{Innovation and education programme development}

The continuing education programme was developed as part of an international and interdisciplinary research project funded by the European Institute of Innovation and Technology (EIT) Health (ID 210638) aimed at furthering 'Patient-centred communication in community pharmacies' (PC3P) by developing and testing a continuing education programme. The overall 
criteria for receiving funding from EIT Health was that the education programme should target either healthcare professionals or executives across Europe, and the funded activities could span one year. Further, the programme would have to prove patient involvement and include online technologies along with evidence-based teaching methods and evaluation frames.

\section{Organisation}

A consortium was developed that included researchers from two European countries: Denmark and the Netherlands. This included the organisations of the Faculty of Health and Medical Sciences and the Faculty of Humanities at the University of Copenhagen, Pharmakon - The Danish College of Pharmacy Practice, University of Southern Denmark, University of Groningen, Netherlands Institute for Health Services Research and Patient in Focus, Denmark. Table I provides an overview of the participants of the consortium.

\section{Table I: Consortium partners}

\begin{tabular}{ll}
\hline & University of Copenhagen: \\
& Faculty of Humanities \\
Denmark & Faculty of Health and Medical Sciences \\
& Pharmakon - The Danish College of Pharmacy Practice \\
& University of Southern Denmark: \\
& Faculty of Health \\
& Patient in Focus \\
\hline The & University of Groningen: \\
Netherlands & Faculty of Science and Engineering \\
& NIVEL (Netherlands Institute for Health Services \\
& Research) \\
\hline
\end{tabular}

The consortium members were included to ensure appropriate and complementary knowledge and skills in developing an education programme and subsequently in running projects and testing the outcome. The researchers of the University of Copenhagen provided the theoretical foundation of the education programme. The pharmacy practice researchers affiliated with the respective universities of Copenhagen, of Southern Denmark and Groningen had extensive experience with and knowledge about the curriculum and training of pharmacy students, whereas researchers from Nivel and Pharmakon had corresponding competencies and knowledge regarding pharmacy technicians and competence development of postgraduate pharmacy staff (pharmacists and pharmacy technicians). The parent organisation of "Patient in Focus" covered the patient perspective and needs, and the practitioners covered the pharmacy workforce's perspective and needs. The mentalising education programme was developed by four Danish consortium members and subsequently translated into English and Dutch in order to be tested in both countries.

\section{Methodological considerations and practical actions}

The methodological considerations for how to develop the course programme were inspired by the part of participatory action research (PAR) (Park, 2001), which involves participation through ongoing dialogue, joint discussions and reflections with patients, community pharmacy staff researchers and the steering group. The antecedent for using this part of PAR is that the programme is developed according to real-life contexts and is thus more likely to be integrated into existing contexts (Park, 2021).

\section{Development participants}

The education programme was primarily developed by the four authoring researchers (henceforth: 'developers'). Four patient volunteers with chronic diseases took medication daily, and practitioners from four different community pharmacies contributed to and co-operated the development process. Throughout the development period, the developers also continuously consulted the pharmacy practice researchers from Copenhagen, Groningen and Nivel at formal steering group meetings every fortnight, thereby ensuring that the programme development was informed by the educational context and background of the programme participants and could work in both Denmark and the Netherlands.

\section{Developers}

The four developers constitute an expert panel within the relevant fields of research, i.e. mentalising, health communication and pharmacy practice. The panel ensures a combination of humanistic and positivistic scientific competencies relevant for the mentalising education programme in a pharmacy context.

\section{Patients}

The four patient volunteers were included with the specific aim of involving individual patient voices and narratives reflecting their experiences as patients and community pharmacy users (Park, 2001). Since mentalising entails meeting patients as unique individuals with specific needs, patients were not only included as representing groups of patients but with the aim of providing unique patient-specific insights for participants to respond to and reflect on. Despite the patients' various conditions, they consistently confirmed the potential of increasing the mentalising capacity in community pharmacies. 


\section{Community pharmacy practitioners}

In total, five practitioners: one pharmacy owner, three pharmacists and one pharmacy technician, were included in the education programme development. The practitioners were included to ensure that the mentalising theory and training were adequately transformed into and compatible with pharmacy practice, hereby certifying the relevance and feasibility of the educational programme (Park 2001).

\section{Timeline of the development process}

The continuing education programme was developed between January 2021 and July 2021. In February 2021, a kick-off meeting with all consortium members took place. The aim was to present the results from the previously mentioned study by Fosgerau \& Kaae (2021) to argue the need for a new education programme for postgraduate community pharmacy staff. Departing from this, mentalising was introduced, explained and suggested as a capacity to include in community pharmacy practice to obtain patient-centred communication. Following this, the developers met for an hour with the patients to learn about their immediate reflections on the potentials and pitfalls of being met by mentalising pharmacy workforce (Park, 2001).

Between February and June, the developers held eight all-day physical workshops and meetings and numerable shorter online meetings. In addition, the developers went on a two-day course to attain knowledge and skills on specific psychological concepts and evaluation measures and to get a common understanding of the core concept of mentalising and how to use this approach in a non-clinical setting.

In March and May of 2021, the developers met with patients for two-three hour meetings. During the first meeting, patients shared their pharmacy experiences and reflected on ways in which their experiences were influenced by the pharmacy staffs' (lack of) mentalising capacity. It was then discussed and jointly decided how patients' individual voices should be directly encompassed during the education: two patients were to be interviewed and recorded, unfolding their personal patient stories. These interviews were decided to be used for the online part of the education. Another two patients were to physically attend the education, also presenting their personal stories (Park, 2001).

One pharmacy practitioner contributed to the programme development by providing insights into the everyday lives of pharmacy practitioners by hosting an excursion for the developers at her pharmacy. This visit gave an authentic impression of the target group of the education programme and the circumstances under which they meet patients. In Denmark, community pharmacy staff have short contact with patients - often two to three minutes at each visit and they have an average of 100 encounters daily. However, many patients with chronic diseases come regularly and pick up their medication at the same community pharmacy, hereby affording the opportunity of viewing patients' pharmacy encounters as a continuous line of short meetings.

In June 2021, the developers met with one pharmacy owner, two pharmacists and one pharmacy technician for two consecutive days to test and get user feedback on the developed education programme material, exercises and theoretical content. This test trial provided insights into the structure and content of the education, which have all subsequently informed the education as it is in its current form. During these activities, the layout, theoretical and practical content of the education programme was discussed and reshaped until deciding on a final form and content. The discussions included perspectives on how to appropriately merge the different and, at times opposing world-views of the humanistic theoretical anchor with the positivistic approach of pharmacy practitioners. The discussions and decisions were informed by the continuous inclusion of researchers from the project consortium and by patients and practitioners. All exercises, teaching materials, legal and instructional documents have been collaboratively produced as a result of these meetings with the various participants (Park, 2001).

Thus, the present continuing education programme has undergone multiple iterations in accommodating perspectives from both the target groups of patients and pharmacy staff through systematic procedures (Park, 2001) while retaining the humanistic, mentalising based approach.

\section{Description of the education programme content}

This section will provide a clarification of the theoretical and pedagogical basis of the education programme. Furthermore, the section provides an overview and description of the education programme modules, the home assignments between all modules and the final report (see Figure 1). 


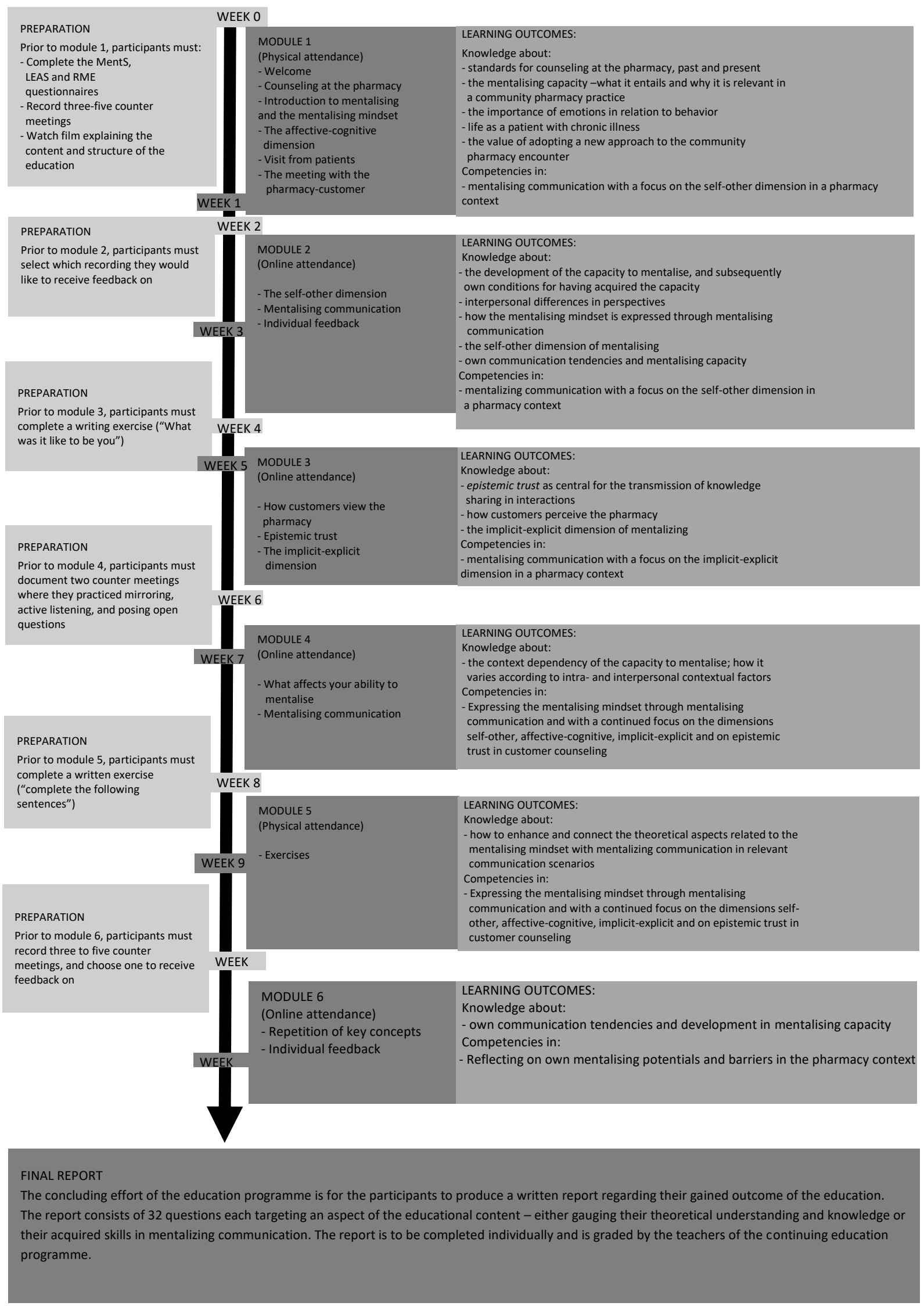

Figure 1: Overview of education programme progression and contents 


\section{The theoretical basis}

Mentalising is a multi-faceted activity, implying that mentalising activities can be characterised according to different dimensions (Bateman \& Fonagy, 2019). Thus, mentalising entails understanding the mental states of both oneself and the other person, forming the selfother dimension. Another dimension is formed by the explicit-implicit polarities referring to mentalising activities as either automatic, immediate and without attentions (implicit) or controlled, reflective and requiring attention (explicit). The third dimension is formed by the affective-cognitive polarities. This dimension emphasises that mentalising is not only governed by cognitive, rational processes but also by emotionality. Essentially, within the framework of mentalising, emotions play a prominent role; learning to understand, recognise and regulate emotions is decisive to a person's personal development and the ability to engage, relate and interact with other people (Allen, 2006). The final and fourth dimension unfolds between internal and external features of mentalising, referring to mentalising processes in which attention is directed either directly towards one's own or others' mental states or towards behaviour and external signals revealing mental states. The dimensions clarify the complexity of the mentalising ability and will to different extents, be included during the course. The theoretical basis of the education programme is structured around the dimensions implicit-explicit, selfother, and affective-cognitive. The fourth (internalexternal) is integrated in the mentalising communication skills training.

Throughout the development of the education programme, it became clear that to increase the community pharmacy workforce's mentalising capacity when engaging with patients; the mentalising concept could benefit from a terminological alteration. Mentalising displays itself in communication and should be trained in this context. However, it is essentially about taking a particular stance, a way of approaching and considering other people, oneself and also the relationships between the parties (Allen, 2003). It is founded in curiosity and interest towards the mental states of other persons and oneself and is considered an attitude more than a skill (Bateman \& Fonagy, 2016). Therefore, profound changes of communicative patterns should rest on incorporation and also training of a specific attitude, a specific mindset. Thus, mentalising is within the context of this education programme separated into two distinct constructs: mentalising mindset and mentalising communication (see Figure 2). Hereby, the multifaceted meaning of the mentalising stance can be teased out, attended to and trained as separate constructs. Thus, by doing so, the intention is to offer an overt understanding of the implicit aspects of mentalising in a comprehensible manner to pharmacists and pharmacy technicians and how to act in accordance with this stance by means of mentalising communication.

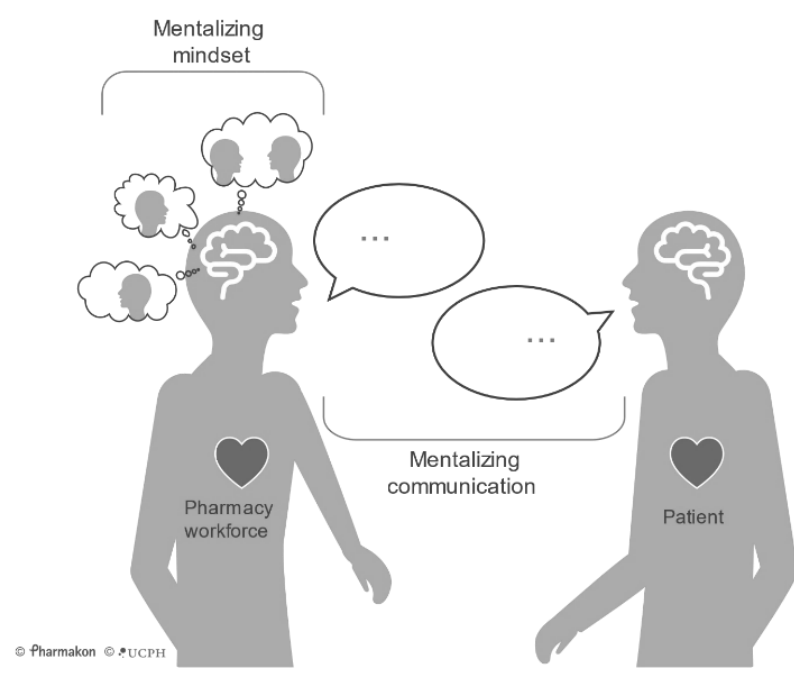

Figure 2: Illustration of the mentalising mindset in combination with the mentalising communication approach

\section{The pedagogical basis}

Essentially, the continuing education programme aims at increasing community pharmacy workforces' mentalising capacity and mentalising communication skills by explaining and informing them about this concept and by providing them with various opportunities to train the capacity. Thus, the education programme is based on a psychoeducational approach (Haslam-Hopwood et al., 2006), providing information about the generic mentalising capacity and, in parallel with the information sharing, training mentalising skills related to a community pharmacy context. Traditionally, psychoeducational approaches have been targeted at either psychiatric patients and/or families with the aim of providing them with information about psychiatric conditions and, on this basis enabling patients to actively engage in the treatment process and families to deliver optimal care that supports patients' treatment (Haslam-Hopwood et al., 2006). However, more recently, psychoeducational interventions targeted at professionals in their day-today practice have been developed with the aim of increasing the professionals mentalising capacity (Bak, 2012; Ensink et al., 2013; Bak et al., 2015; Valle et al., 2016; Schwarzer et al., 2021), and hereby the ability to better understand the intentional mental states of both themselves and the citizens that they serve. A central part of these psychoeducational interventions is that 
they not only focus on teaching the content of mentalizing but also include activities that train the participants' mentalising skills (Haslam-Hopwood et al., 2006).

The pedagogical considerations for how to increase community pharmacy staffs mentalising ability by teaching the concept of mentalising and practising mentalising communication is based on learning theory (Illeris, 2009). Figure 3 illustrates the different components that are used when delivering the education to the pharmacy workforce, i.e. a group of participants with a natural science background, with expertise in medicine and use of medicine. The elements reflect that the new knowledge regarding the mentalising mindset and mentalising communication should be linked closely to the existing and often tacit knowledge on everyday community pharmacy practice. This is done to help the participants take up the new knowledge within a familiar frame of reference where they feel confident in their daily practice. The participants will learn to become more aware of the humanistically rooted, interactional skills and be able to use these skills together with their knowledge on medicine and medicine use.

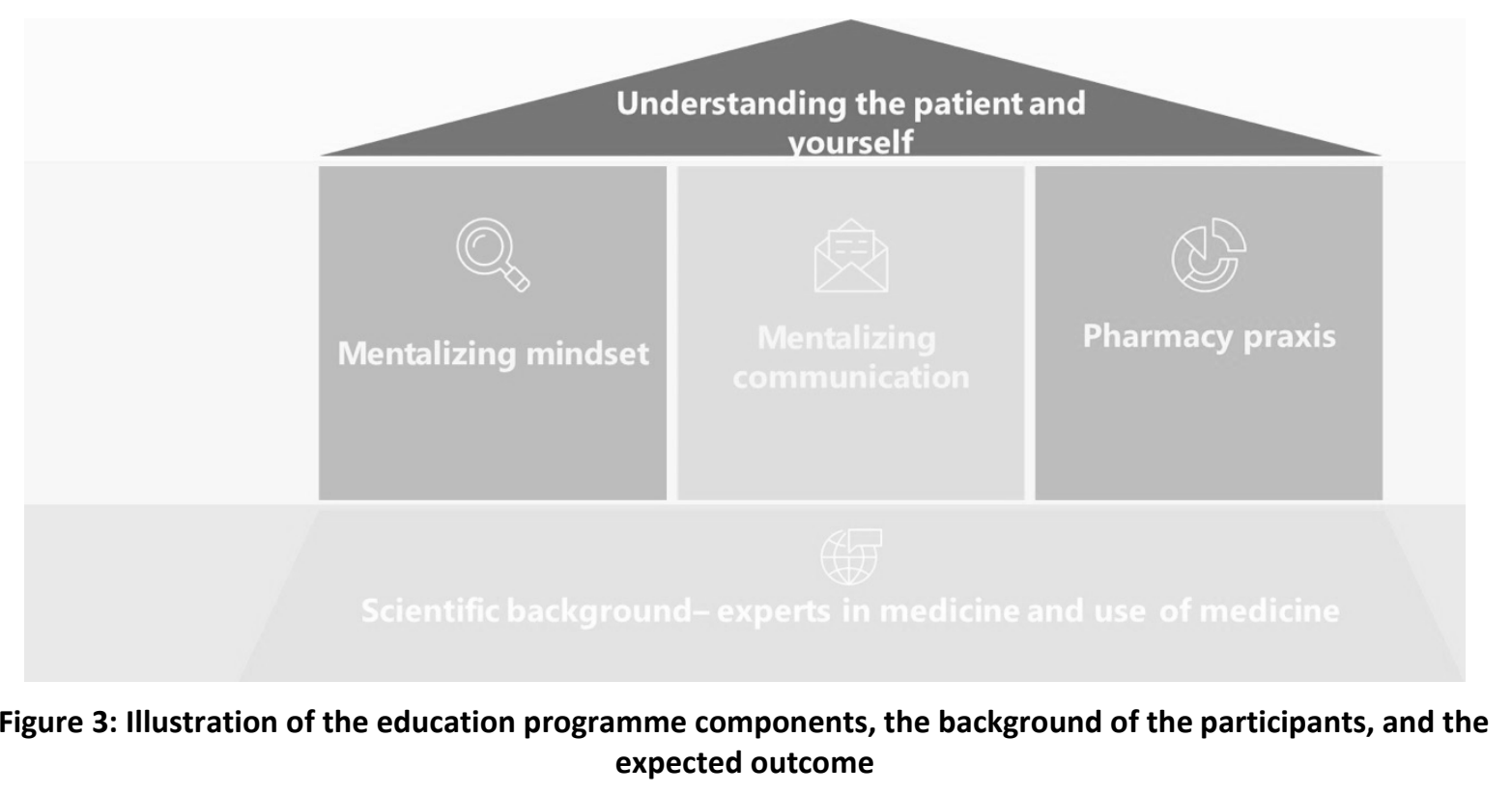

To ensure this transfer between learning from a theoretical context (the classroom) to a real-life context, which in this case is the community pharmacy, a shift between theoretical teaching lessons and presentations, individual and group communication training activities, and role-play will take place while having the participants' scientific background, education and work setting in mind (Wahlgren, 2009). Table II provides an overview of the elements and activities used for this purpose. It is important to mention that all activities will be used and combined throughout the entire education to suit the individual theme and aim.

Feedback is a central part of the education programme as it allows participants to engage critically with their own behaviour in the desk meetings. All feedback is structured according to the Video Stimulated Recall Interview (VSRI) format (Pomerantz, 2005), which entails that participants will be asked to share their experiences as they interacted with the patients, i.e. how did they feel at the time of the pharmacy

interaction, how did they consider the patient and the patient's mental states, how do they consider and assess their communication skills, what kind of conversation took place - was it led by the patient or by the staff. Such explorations are in and of themselves mentalising activities, and the feedback format hereby facilitates training participants' mentalising capacity and communication skills.

Furthermore, with reference to the mentalising concepts and the mentalising communication introduced during the education until the times of the individual or group feedback, the teacher/developers will comment on and designate points of attention for the participants to work with continuously during the education and in their professional practice when returning to the community pharmacies. 
Table II: Presentation of core activities employed to secure a comprehensible combination of the mentalising mindset and communication

\begin{tabular}{ll}
\hline Communication models & - Orlando, 1961 \\
& - Zoffmann et al., 2008 \\
- Zoffmann \& Kirkevold, 2005) & - Individual worksheets \\
communication training & - Mirroring (Clabby \& O'Connor, \\
& 2004) \\
& - Active listening \\
& - Response models (Gordon \& \\
& Kragh, 1999) \\
& - Values clarification (Poulsen, \\
& 2010; Steinberg \& Andresen, \\
& 1981) \\
\hline Oral communication & Role-play \\
training sessions with & Patient interviews \\
the use of patient cases & - Patient narratives \\
\hline Video recordings of & - One-on-one feedback \\
desk meetings & structured according to video \\
& stimulated recall-interview \\
& format (VSRI) (Fosgerau \& Kaae, \\
& 2021) (Larsen 1998) \\
\hline
\end{tabular}

\section{The content of the education programme}

The education programme consists of six modules that span four months (see table II). Module one and module five are physical attendance days. Module one covers one and a half-day, whereas module five covers one full working day. The physical attendance days will focus on combining the theoretical mentalising concepts, i.e. the participants' mentalising mindset and mentalising communication skills. Modules two - six are online modules of four hours duration. These modules will each focus on different theoretical aspects of the education programme combined with individual or group exercises in mentalising communication. Module six is designated to repeat the core constructs and instructions to produce a written report to be handed in four weeks after the last module. The working load for participating in the education programme is estimated to be 70 hours equivalent to 3.5 European Credit transfer and Accumulation System (ECTS) points and comprises the actual modules, homework between modules and the final report. All modules are concluded by a module evaluation and preparation for the relevant home-assignment.

\section{Evaluation}

The programme will be evaluated using the Kirkpatrick model (Kirkpatrick \& Kirkpatrick, 2016) and thus evaluated according to four levels: 1) Reaction; 2) Learning; 3) Behavior; and 4) Results. The results will provide feedback to explore the intended effect of the programme, i.e. a potential increase in participants' mentalising capacity (level 3 ) and a potential increase in their ability to promote patients' perspective sharing during the pharmacy encounter (level 3). Also, the evaluation will attend to aspects related to the education programme's potential effect on the participants' work-related mental health by measuring job satisfaction (level 4). Further, even though this is complex to grasp, the evaluation will also tap into the ultimate goal of the education programme, i.e. to see if the education programme enables the pharmacy workforce to better help patients improve their medication use (level 4). The results from the comprehensive evaluation based on the Kirkpatrick model will also function to inform modifications of the education programme for future use.

\section{Level 1: Reaction}

The individual modules will be evaluated in detail. The focus for evaluation will be feedback on the topics, exercises and teachers. Additionally, after the last module, the participants will express their overall satisfaction with the education programme using the validated Course Experience Questionnaire (Wilson et al., 1997).

\section{Level 2: Learning}

After module six, participants will hand in a written report to illustrate that they have attained the knowledge and skills central to the education programme. This implies knowledge of how to interact with pharmacy patients in a mentalising manner - both in regards to the mentalising mindset and communication. The final report is structured to elicit participants' knowledge of when and how to employ the communication tools provided during the education programme.

\section{Level 3: Behaviour}

Prior to modules one and module five, each participant records between three and five videos of real-life encounters with patients at their pharmacy, and in modules two and five, participants will receive individual feedback on the videos. Thus, the videos are included with a pedagogical, learning purpose. Furthermore, the videos will reflect if the gained knowledge and skills have been transferred to participants' behaviour at the pharmacy desk. In addition, various assessments tools targeting participants' mentalising capacity are also included. Prior to Module one, participants are to fill out three different questionnaires: MentS (Dimitrijević et al., 2018), Level of Emotional Awareness Scale (LEAS) (Lane 
et al., 1990) and Reading the Mind in the Eyes (RME) (Baron-Cohen \& Wheelwright, 2001) are included for evaluative measures. After terminating the education, participants are to fill out the same three questionnaires to explore potential progressions in their mentalising capacity. While the assessment tools are not a direct measure of behavior, they do express participants' mentalising mindset, which presumably reflects behavior.

\section{Level 4: Results}

Participants will report if and how the mentalising education programme influence their job satisfaction by filling out the validated 'Measuring Job Satisfaction' (Traynor \& Wade, 1993) before and after the education. Further, participants will register before and after the education, how many and which type of drugrelated problem they detect when communicating at the pharmacy counter with patients picking up prescription medicine. In addition, the potential direct effects on patients are measured by researchers from the consortium being present in the pharmacies, asking patients with prescription medicine who had medicine dispensed by participants how they perceived the communication and their perceived outputs of the communication by using the validated 'Communication Assessment Tool' (Makoul et al., 2007) and the 'Patient Empowerment Indicator' (Cerezo et al., 2016), also collected as pre/post measurements.

\section{Implementation}

If the mentalising education programme proves to be effective in relevant aspects, it will be distributed to the pharmacy workforce in Denmark and The Netherlands. The plan is to develop an online mentalising community where trainers and professionals can interact and exchange ideas and experiences and further be updated through webinars, tutorials, etc. Hereby, implementation of the mentalising practices into daily pharmacy practice is supported, and participants are enabled to keep developing their mentalising skills. Based on the evaluation, the consortium members will likewise start making plans for how to transfer/ transform the mentalising education to the basic curriculum of pharmacists and pharmacy technicians. Hereby the mentalising approach can become an even further integrated part of pharmacy communication practice, should it turn out to effectively change participants' mentalising capacity and thus ways of actively engaging patients' perspectives during the pharmacy encounter.

\section{Acknowledgements}

The authors thank EIT Health, University of Groningen, Nivel, Patient in Focus, psychologist and mentalising expert Jens Hardy Soerensen, and contributing pharmacy practitioners for their contribution to the development of the continuing education programme.

\section{Declaration of interest}

The authors found no conflict of interest and are solely responsible for the content and writing of the article.

\section{References}

Allen, J.G. (2003). Mentalising. Bulletin of the Menninger Clinic, 67(2), 91-112. SciTech Premium Collection. https://doi.org/10.1521/bumc.67.2.91.23440

Allen, J.G. (2006). Mentalising in Practice. In J. G. Allen \& P. Fonagy (Eds.), Handbook of Mentalisation-Based Treatment (pp. 1-30). John Wiley \& Sons, Ltd.

https://doi.org/10.1002/9780470712986.ch1

Bak, P.L. (2012). Promoting mentalising communities for children. In N. Midgley \& I. Vrouva (Eds.), Minding the child: Mentalization-based interventions with children, young people and their families (pp. 202-217). Routledge/Taylor \& Francis Group

Bak, P.L., Midgley, N., Zhu, J.L., Wistoft, K., \& Obel, C. (2015). The Resilience Program: Preliminary evaluation of a mentalisation-based education program. Frontiers in Psychology, 6. https://doi.org/10.3389/fpsyg.2015.00753

Baron-Cohen, S., \& Wheelwright, S. (2001). The "Reading the Mind in the Eyes" Test Revised Version: A Study with Normal Adults, and Adults with Asperger Syndrome or Highfunctioning Autism. Journal of Child Psychology \& Psychiatry \& Allied Disciplines, 42(2), 241.

https://doi.org/10.1111/1469-7610.00715

Bateman, A., \& Fonagy, P. (2016). Mentalisation-Based Treatment for Personality Disorders: A Practical Guide. Oxford University Press, Incorporated. Available at : http://ebookcentral.proquest.com/lib/kbdk/detail.action?d oclD=4413992

Bateman, A.W., \& Fonagy, P. (2019). Handbook of Mentalising in Mental Health Practice. American Psychiatric Publishing. Available at:

http://ebookcentral.proquest.com/lib/kbdk/detail.action?d ocID $=5790646$

Benrimoj, S.I., \& Fernandez-Llimos, F. (2020). An international series on the integration of community pharmacy in primary health care. Pharmacy Practice, 18(1), 1878. https://doi.org/10.18549/PharmPract.2020.1.1878

Bridgeman, P.J., Bridgeman, M.B., \& Barone, J. (2018). Burnout syndrome among healthcare professionals. American Journal of Health-System Pharmacy, 75(3), 147152. https://doi.org/10.2146/ajhp170460 
Cerezo, P.G., Juvé-Udina, M.-E., \& Delgado-Hito, P. (2016). Concepts and measures of patient empowerment: A comprehensive review. Revista Da Escola de Enfermagem Da USP, 50(4), 667-674. https://doi.org/10.1590/S0080623420160000500018

Ceulemans, M., Liekens, S., Van Calsteren, K., Allegaert, K., \& Foulon, V. (2021). Impact of a blended learning program on community pharmacists' barriers, knowledge, and counseling practice with regard to preconception, pregnancy and lactation. Research in Social and Administrative Pharmacy, 17(7), 1242-1249. https://doi.org/10.1016/j.sapharm.2020.09.009

Chong, W.W., Pharm, B., Aslani, P., \& Chen, T.F. (2014). Pharmacist-patient communication on use of antidepressants: A simulated patient study in community pharmacy. Research in Social and Administrative Pharmacy, 19. https://doi.org/10.1016/j.sapharm.2013.05.006

Clabby, J., \& O'Connor, R. (2004). Teaching Learners to Use Mirroring: Rapport Lessons From Neurolinguistic Programming. Family Medicine, 36(8), 541-543

Dimitrijević, A., Hanak, N., Altaras Dimitrijević, A., \& Jolić Marjanović, Z. (2018). The Mentalisation Scale (MentS): A Self-Report Measure for the Assessment of Mentalizing Capacity. Journal of Personality Assessment, 100(3), 268280. https://doi.org/10.1080/00223891.2017.1310730

Ensink, K., Maheux, J., Normandin, L., Sabourin, S., Diguer, L., Berthelot, N., \& Parent, K. (2013). The impact of mentalization training on the reflective function of novice therapists: A randomized controlled trial. Psychotherapy Research, 23(5), 526-538.

https://doi.org/10.1080/10503307.2013.800950

Fosgerau, C.F., \& Kaae, S. (2021). Furthering patientcentered counseling: Exploring new aspects around pharmacists' experiences in pharmacy encounters through video-stimulated recall interviewing. Research in Social and Administrative Pharmacy, 17(4), 723-732.

https://doi.org/10.1016/j.sapharm.2020.06.018

Gordon, T., \& Kragh, B. (1999). Forældreuddannelse: Problemer, konflikter, løsninger / Parent effectiveness training (3rd ed.). Borgen

Haslam-Hopwood, G.T.G., Allen, J.G., Stein, A., \& Bleiberg, E. (2006). Enhancing Mentalizing Through Psycho-Education. In J. G. Allen \& P. Fonagy (Eds.), Handbook of MentalizationBased Treatment.

https://doi.org/10.1002/9780470712986.ch13

Illeris, K. (2009). Transfer of learning in the learning society: How can the barriers between different learning spaces be surmounted, and how can the gap between learning inside and outside schools be bridged? International Journal of Lifelong Education, 28(2), 137-148.

https://doi.org/10.1080/02601370902756986

Kaae, S., Mygind, A., \& Saleem, S. (2013). A characterization of the current communication patterns in Danish community pharmacies - An observational study. Research in Social and Administrative Pharmacy, 9(6), 958-964. https://doi.org/10.1016/j.sapharm.2012.10.003
Kaae, S., Traulsen, J.M., \& Nørgaard, L.S. (2014). Customer interest in and experience with various types of pharmacy counselling-A qualitative study. Health Expectations, 17(6), 852-862. https://doi.org/10.1111/hex.12003

Kari, H., Kortejärvi, H., Airaksinen, M., \& Laaksonen, R. (2018). Patient involvement is essential in identifying drugrelated problems. 11. https://doi.org/10.1111/bcp.13640

Kirkpatrick, J.D., \& Kirkpatrick, W.K. (2016). Kirkpatrick's Four Levels of Training Evaluation. Association for Talent Development

Koster, E.S., van Meeteren, M.M., van Dijk, M., van den Bemt, B.J.F., Ensing, H.T., Bouvy, M.L., Blom, L., \& van Dijk, L. (2015). Patient-provider interaction during medication encounters: A study in outpatient pharmacies in the Netherlands. Patient Education and Counseling, 98(7), 843848. https://doi.org/10.1016/j.pec.2015.03.007

Lane, R.D., Quinlan, D.M., Schwartz, G.E., Walker, P.A., \& Zeitlin, S.B. (1990). The Levels of Emotional Awareness Scale: A Cognitive-Developmental Measure of Emotion. Journal of Personality Assessment, 55(1/2), 124. https://doi.org/10.1080/00223891.1990.9674052

Langberg, E.M., Dyhr, L., \& Davidsen, A.S. (2019). Development of the concept of patient-centredness - A systematic review. Patient Education and Counseling, 102(7), 1228-1236.

https://doi.org/10.1016/j.pec.2019.02.023

Liekens, S., \& Foulon, V. (2019). Pharmaceutical Care and the Role of the Patient. In F. Alves da Costa, J.W.F. van Mil, \& A. Alvarez-Risco (Eds.), The Pharmacist Guide to Implementing Pharmaceutical Care (pp. 25-31). Springer International Publishing. https://doi.org/10.1007/978-3319-92576-9_3

Liekens, S., Vandael, E., Roter, D., Larson, S., Smits, T., Laekeman, G., \& Foulon, V. (2014). Impact of training on pharmacists' counseling of patients starting antidepressant therapy. Patient Education and Counseling, 94(1), 110-115. https://doi.org/10.1016/j.pec.2013.09.023

Makoul, G., Krupat, E., \& Chang, C.-H. (2007). Measuring patient views of physician communication skills: Development and testing of the Communication Assessment Tool. Patient Education and Counseling, 67(3), 333-342. https://doi.org/10.1016/j.pec.2007.05.005

Murad, M.S., Spiers, J.A., \& Guirguis, L.M. (2017). Expressing and negotiating face in community pharmacist-patient interactions. Research in Social and Administrative Pharmacy, 13(6), 1110-1126.

https://doi.org/10.1016/j.sapharm.2016.10.003

Olsson, E., Ingman, P., Ahmed, B., \& Kälvemark Sporrong, S. (2014). Pharmacist-patient communication in Swedish community pharmacies. Research in Social and Administrative Pharmacy, 10(1), 149-155. https://doi.org/10.1016/j.sapharm.2013.03.001

Orlando, I.J. (1961). The dynamic nurse-patient relationship: Function, process, and principles. G.P. Putnam

Padgett, E.H., \& Grantner, G.R. (2020). Pharmacist Burnout and Stress. U.S. Pharmarcist, 45(5). 
https://www.uspharmacist.com/article/pharmacistburnout-and-stress

Park, P. (2001). Knowledge and Participatory Research. In P. Reason \& H. Bradbury (Eds.), Handbook of Action Research: Participative Inquiry and Practice

Patwardhan, P.D., Amin, M.E., \& Chewning, B.A. (2014). Intervention research to enhance community pharmacists' cognitive services: A systematic review. Research in Social and Administrative Pharmacy, 10(3), 475-493.

https://doi.org/10.1016/j.sapharm.2013.07.005

Pomerantz, A. (2005). Using participants' video-stimulated comments to complement analyses of interactional practices. In H. te Molder \& J. Potter (Eds.), Conversation and Cognition (pp. 93-113). Cambridge University Press; Cambridge Core.

https://doi.org/10.1017/СBO9780511489990.005

Poulsen, A. (2010). Aktive vurderinger: En sundhedspædagogisk metode til værdiafklaring (1st ed.). Komiteen for Sundhedsoplysning

Presley, B., Groot, W., \& Pavlova, M. (2019). Pharmacy-led interventions to improve medication adherence among adults with diabetes: A systematic review and metaanalysis. Research in Social and Administrative Pharmacy, 15(9), 1057-1067.

https://doi.org/10.1016/j.sapharm.2018.09.021

Qudah, B., Thakur, T., \& Chewning, B. (2021). Factors influencing patient participation in medication counseling at the community pharmacy: A systematic review. Research in Social and Administrative Pharmacy, S155174112100111X. https://doi.org/10.1016/j.sapharm.2021.03.005

Satran, C., Tsamri, R., Peled, O., Zuker, H., Massalha, L., \& Ore, L. (2020). A unique program for nursing students to enhance their mentalization capabilities in relation to clinical thinking. Journal of Professional Nursing, 36(5), 424431. https://doi.org/10.1016/j.profnurs.2020.03.010

Schwarzer, N.-H., Nolte, T., Fonagy, P., Griem, J., Kieschke, U., \& Gingelmaier, S. (2021). The relationship between global distress, mentalizing and well-being in a German teacher sample. Current Psychology. https://doi.org/10.1007/s12144-021-01467-3

Steed, L., Sohanpal, R., Todd, A., Madurasinghe, V.W., Rivas, C., Edwards, E. A., Summerbell, C. D., Taylor, S. J., \& Walton, R. (2019). Community pharmacy interventions for health promotion: Effects on professional practice and health outcomes. Cochrane Database of Systematic Reviews. https://doi.org/10.1002/14651858.CD011207.pub2

Steinberg, J.M., \& Andresen, A.F. (1981). Aktivt verdivalg: Meninger og handlinger: En pedagogisk metodikk (Active choice of values. Opinions and Actions. A pedagolocial methodology)

Svensberg, K., Björnsdottir, I., \& Kälvemark Sporrong, S. (2015). Legal cognitive requirements impact on pharmacy practice and patient outcomes. Research in Social and Administrative Pharmacy, 11(4), 590-591. https://doi.org/10.1016/j.sapharm.2015.01.003

Traynor, M., \& Wade, B. (1993). The development of a measure of job satisfaction for use in monitoring the morale of community nurses in four trusts. Journal of Advanced Nursing, 18(1), 127-136. https://doi.org/10.1046/j.13652648.1993.18010127.x

Valle, A., Massaro, D., Castelli, I., Sangiuliano Intra, F., Lombardi, E., Bracaglia, E., \& Marchetti, A. (2016). Promoting Mentalizing in Pupils by Acting on Teachers: Preliminary Italian Evidence of the "Thought in Mind" Project. Frontiers in Psychology, 7. https://doi.org/10.3389/fpsyg.2016.01213

Wahlgren, B. (2009). Transfer mellem uddannelse og arbejde.

Welstead, H.J., Patrick, J., Russ, T.C., Cooney, G., Mulvenna, C.M., Maclean, C., \& Polnay, A. (2018). Mentalising skills in generic mental healthcare settings: Can we make our dayto-day interactions more therapeutic? BJPsych Bulletin, 42(3), 102-108. https://doi.org/10.1192/bjb.2017.29

Wilson, K.L., Lizzio, A., \& Ramsden, P. (1997). The development, validation and application of the Course Experience Questionnaire. Studies in Higher Education, 22(1), 33-53.

https://doi.org/10.1080/03075079712331381121

Wolters, M., van Hulten, R., Blom, L., \& Bouvy, M.L. (2017). Exploring the concept of patient centred communication for the pharmacy practice. International Journal of Clinical Pharmacy, 39(6), 1145-1156. https://doi.org/10.1007/s11096-017-0508-5

Zoffmann, V., Harder, I., \& Kirkevold, M. (2008). A PersonCentered Communication and Reflection Model: Sharing Decision-Making in Chronic Care. Qualitative Health Research, 18(5), 670-685. https://doi.org/10.1177/1049732307311008

Zoffmann, V., \& Kirkevold, M. (2005). Life Versus Disease in Difficult Diabetes Care: Conflicting Perspectives Disempower Patients and Professionals in Problem Solving. Qualitative Health Research, 15(6), 750-765. https://doi.org/10.1177/1049732304273888 